\title{
Papas Nativas - Un cultivo con potencial de alto valor añadido para la agricultura sostenible
}

\author{
E. Ritter ${ }^{1}$, J. Ruiz de Galarreta ${ }^{1}$, L. Barandalla ${ }^{1}$, R. López ${ }^{1}$, M. Huarte ${ }^{2}$, S. Capezzio ${ }^{2}$, X. \\ Cuesta $^{3}$, J. Rivadeneira ${ }^{3}$, F. Vilaró ${ }^{4}$, J. Gabriel ${ }^{5}$, M. Scurrah ${ }^{6}$, R. Canto ${ }^{6}$, W. Amoros ${ }^{7}$, A. \\ Forbes $^{7}$, M. Bonierbale ${ }^{7}$
}

RESUMEN

Un consorcio de siete socios de seis países iberoamericanos ha evaluado diferentes propiedades de una colección de Papas Nativas. Las evaluaciones incluyen resistencias a diferentes plagas y enfermedades, cualidades nutricionales y sustancias perjudiciales, comportamiento agronómico, análisis de la aptitud para el procesado y calidad organoléptica. Se han encontrado características favorables para todos los caracteres estudiados en algunos de los genotipos de Papas Nativas. Estos estudios se completaron con un análisis de la biodiversidad molecular existente para genes candidatos de resistencia y calidad.

Palabras claves: biodiversidad, fitopatología, procesamiento, mejora genética

\section{Native Potatoes - A crop with potential for high added value for sustainable agriculture}

\begin{abstract}
A consortium of seven members from six countries has evaluated different properties of a collection of Native Potatoes. The evaluations include resistances to different pest and diseases, nutritional quality and noxious substances, agronomic performance, aptitude for processing and culinary properties. Favourable characteristics were found for all studied characters in some of the genotypes. These studies were completed by an analysis of the molecular biodiversity of candidate genes for resistances and quality in the collection.
\end{abstract}

Keywords: biodiversity, phytopathology, processing, breeding

\footnotetext{
${ }^{1}$ NEIKER, Instituto Vasco de Investigación y Desarrollo Agrario, Apartado 46, Vitoria, España. eritter@neiker.net

${ }^{2}$ Instituto Nacional de Tecnología Agropecuaria (INTA), Estación Experimental Agropecuaria Balcarce, Ruta 226 Km 73.5. CC 276 (7620), Buenos Aires, Argentina. huarte@balcarce.inta.gov.ar

${ }^{3}$ Instituto Nacional Autónomo de Investigaciones Agropecuarias (INIAP), Estación Experimental Santa Catalina, Panamericana Sur km 1, Quito, Ecuador, cuesta@fpapa.org.ec

${ }^{4}$ Instituto Nacional de Investigación Agropecuaria (INIA), Estación Experimental Las Brujas, Ruta 48 Km. 10, Canelones, Uruguay. fvilaro@inia.org.uy

${ }^{5}$ Fundación Promoción e Investigación de Productos Andinos (PROINPA), P.O. Box 4285, Cochabamba, Bolivia. j.gabriel@proinpa.org

${ }^{6}$ Grupo Yanapai, Atahualpa 297, Concepción, Junín, Perú. m.scurrah@cgiar.org

${ }^{7}$ Centro Internacional de la Papa (CIP), Apartado 1558, Lima 12, Perú. m.bonierbale@cgiar.org
} 


\section{Introducción}

Las "Papas nativas" (PN) son especies cultivadas del genero Solanum, que no pertenecen a las papas comunes (Solanum tuberosum ssp.). Producen tubérculos variopintos y se cultivan bajo duras condiciones ambientales donde las variedades comerciales no pueden competir. Durante siglos estas PN han sido localmente seleccionadas por los campesinos andinos con el fin de subsistir bajo las severas condiciones ambientales de los Andes. Dichos agricultores han sido capaces de seleccionar y mantener una alta diversidad de germoplasma con excelentes cualidades organolépticas, cultivando $\mathrm{PN}$ de diferentes ploidías, resistencia a enfermedades y estreses abióticos dentro de una misma parcela de cultivo (Bonierbale et al., 2004). Sin embargo, hasta hoy estos valiosos recursos no han sido explotados eficientemente a causa del aislamiento geográfico (Huanco, 1991). En el marco del proyecto "Papasalud", un consorcio de siete participantes de seis países (Argentina, Bolivia, Ecuador, España, Perú y Uruguay) ha evaluado las propiedades de PN.

El objetivo general del proyecto consiste en seleccionar y desarrollar PN con mayor rendimiento y calidad y adaptadas a diferentes estreses ambientales para la agricultura sostenible en las zonas andinas de América del Sur, así como estimular su explotación como nuevos productos de mercado, aportando al mismo tiempo nuevas fuentes de genes de resistencia y de calidad para la mejora genética en patata.

\section{Materiales y métodos}

En el marco del proyecto se manejan por los participantes alrededor de 350 entradas de PN y variedades antiguas, aparte de numerosas progenies que resultan del plan de mejora asociado. Una serie de testigos comunes sirven como referencia en los ensayos. Se han realizado las siguientes evaluaciones en estos materiales utilizando metodología estándar: caracterización morfológica y fisiológica según Gómez (2000); análisis y evaluaciones de resistencias a plagas y enfermedades (virus, nematodos, Phytophthora, Alternaria, Streptomyces, Pectobacterium y Rhizoctonia) en bioensayos y ensayos de campo; análisis de sustancias perjudiciales (glicoalcaloides, nitratos, acrilamida); cualidades nutricionales considerando la composición general y los contenidos de minerales $\mathrm{y}$ micronutrientes; análisis de diferentes vitaminas y sustancias antioxidantes; ensayos de campo en varias localidades para evaluar el comportamiento agronómico; y análisis de la aptitud para el procesado y la calidad organoléptica (materia seca, azúcares reductores, chips, fritura francesa, cocción). Estas caracterizaciones fenotípicas se han completado con un análisis de la biodiversidad molecular para genes candidato de resistencia y calidad.

\section{Resultados y Discusión}

Los detalles sobre el material vegetal, la metodología y todos los resultados obtenidos se muestran en la página Web del proyecto: http://www.neiker.net/neiker/papasalud. En general, se han identificado para todos los caracteres evaluados genotipos superiores con resistencias (múltiples) a diferentes estreses bióticos y abióticos, con buenas características agronómicas, con calidades organolépticas excelentes y con buena aptitud para las diferentes formas de procesamiento. Además se han obtenido, a través de la mejora, nuevos genotipos con combinaciones de caracteres favorables y se han determinado prácticas apropiadas para el cultivo, manejo y el uso de las PN.

Los marcadores obtenidos para genes útiles en la caracterización molecular pueden orientar en la conservación de germoplasma y proporcionan herramientas eficientes para la selección asistida. También se han realizado diferentes acciones de promoción y explotación de las PN basados en el análisis de su aptitud para el mercado y los costos de producción. 


\section{Conclusiones}

Las PN tienen el potencial de aumentar su superficie de cultivo, de diversificar la producción agraria, de asegurar el suministro de alimentos en zonas deprimidas, y de aumentar los ingresos abriendo, inclusive mercados de exportación. El cultivo de genotipos adecuados con resistencias, buena calidad y adaptación a ambientes agroclimáticos específicos, así como su manejo apropiado permitirá reducir los costos de producción, contribuyendo de esta forma al desarrollo sostenible y al incremento de la calidad de vida. Por otra parte los genotipos de PN con características superiores identificados o desarrollados tienen un alto valor para la mejora genética convencional de la patata.

\section{Agradecimientos}

Parte de este trabajo es financiado por el marco del proyecto del Programa Iberoamericano de Ciencia y Tecnología para el Desarrollo (CYTED), España 407PIC0306 (Papasalud) y por el Instituto Nacional de Investigación Agraria (INIA), España (RTA2008-00045-C0201).

\section{Literatura citada}

Bonierbale, M., Amoros, W., Gómez, R., Bernet, T. 2004. Value-added options for native potato diversity. American Journal of Potato Research 81: 47.

Gómez, R. 2000. Guía para las caracterizaciones morfológicas básicas en colecciones de papas nativas. Centro Internacional de la Papa (CIP), Germoplasma de Papa, Dpto. de Mejoramiento y Recursos Genéticos. CIP, Lima, Perú, 7 p.

Huanco, V. 1991. Potencial de las papas amargas en el altiplano de Puno. Perú. (pp 25-26). En: Rea, J., Vacher, J. J. (ed.). La papa amarga. Primera Mesa Redonda: Perú-Bolivia, La Paz, 7 y 8 de Mayo, 1991. Orstom, La Paz, Bolivia. 35 p. 